\title{
EVALUATION OF THE MECHANICAL PROPERTIES AND SURFACE TOPOGRAPHY OF AS-RECEIVED, IMMERSED AND AS-RETRIEVED ORTHODONTIC ARCHWIRES
}

\author{
SILVIA IZABELLA POP ${ }^{1}$, MIRCEA DUDESCU ${ }^{2}$, \\ VIOLETA VALENTINA MERIE ${ }^{2}$, MARIANA PACURAR ${ }^{1}$, \\ CRISTINA DANA BRATU ${ }^{3}$
}

\author{
${ }^{1}$ Orthodontics Department, University of Medicine and Pharmacy, Tg Mures, \\ Romania \\ ${ }^{2}$ Department of Mechanical Systems Engineering, Technical University, \\ Cluj-Napoca, Romania \\ ${ }^{3}$ Orthodontics Department. Victor Babes University of Medicine and Pharmacy, \\ Timisoara, Romania
}

\begin{abstract}
Background and aims. This experimental study mainly aims at comparing the most important mechanical properties of the new orthodontic archwires, those immersed in fluorinated solution, the as-retrieved ones and the intra-oral used ones.

Methods. A total of 270 arch wires were tested, using tensile testing and threepoint bending tests. The tested archwires were made of Stainless Steel, Nickel Titanium, Beta-Titanium and physiognomic covered Nickel Titanium. The tested archwires were subjected to three types of treatments: immersion into fluorinated solution, immersion into carbonated drinks and intra-oral use.

Results. The immersion caused variations of the activation and deactivation forces of all arch wires. The most affected arch wires, in terms of bending characteristics, were the intra-oral used ones.

Conclusions. The alteration of mechanical properties of the orthodontic arch wires by their immersion into fluorinated solutions and soft drinks could not be statistically demonstrated.
\end{abstract}

Keywords: orthodontic archwires, nickel titanium, stainless steel, betatitanium, mechanical testing

\section{Background and aims}

The orthodontic biomechanics is based on the principle of elastic energy storage and its conversion into mechanical energy during the tooth movement [1]. The optimal control of the tooth movement requires the application of a special force system, by using some accessory elements such as the archwires. Despite of the considerable number of existing commercial brands and their aggressive advertising, the most used dental arches

Manuscript received: 30.09.2016

Received in revised form: 09.11.2016

Accepted: 22.11.2016

Address for correspondence: kecsetisilvia@yahoo.com remain the stainless steel (SS) archwires, nickel titanium (NiTi) and beta-titanium ( $\beta$-Ti). In addition to these, the metal aesthetic coated archwires and the physiognomic non-metal coated archwires are more and more known [1].

In the last decades numerous studies [2-9,10,11] have been focused on evaluating the mechanical and surface properties of new archwires. During the orthodontic treatment, the archwires are exposed to the action of different acid or alkaline substances and the changes due to these chemicals on the surface and structure and, therefore, on the clinical efficacy of metal alloys are less known. Also, the difficulty of reproduction in vitro of the multitude 


\section{Dental Medicine}

and of the variety of factors present in the oral cavity during the orthodontic treatment impede even more the transposition and interpretation of results in the orthodontic biomechanics.

In his recent study, Bellini et al. [12] evaluated and compared the mechanical properties of eight widely used orthodontic Ni-Ti archwires, independently of trade houses and under the same standardized testing conditions. The effect of the thermal treatments on the mechanical behavior and the microstructure of $\mathrm{Ni}-\mathrm{Ti}$ archwires of different compositions was also studied [12]. Obaisi et al. [13] determined the transformation temperatures of two brands of heat-activated $\mathrm{Ni}$-Ti orthodontic archwires using both the Bend and Free Recovery (BFR) method and the standard method of Differential Scanning Calorimetry (DSC). Muguruma et al. [14] analyzed the coatings covering esthetic orthodontic wires and the influence of such coatings on bending and frictional properties. They demonstrated that orthodontic coated wires with small inner alloy cores withstand less force than expected and may be unsuitable for establishing sufficient tooth movement.

One of the keys to success of the orthodontic treatment is to maintain the oral hygiene and the caries control [1517]. Thus, the daily use of the fluoride preparations on the recommendation of an orthodontist is a prophylactic method often used to prevent white spot lesions [16,17]. However, it was shown that the fluoride ions of the fluoride preparations may cause corrosion phenomena, the color change of the orthodontic archwires and the alteration of the mechanical properties, especially the frictional properties [15]. Also, there are numerous studies [15,18,19-21,2232] concerning how the fluoride concentration, the time exposure and the acidity of the solution cause changes to the archwires properties. Studies related to soft drinks [3335] are focused on their effect on the enamel structure and on the interference with the bracket adhesion $[33,35]$ and only a few of them evaluate their effect on the mechanical properties of the archwires [35].

During the orthodontic treatment, the orthodontic archwires are subject to numerous factors and variables present into the oral cavity [36]. The assessment of the surface morphology of these intra-orally used archwires was the purpose of numerous studies [37-43]. However, there are only a few works in which the study the mechanical properties of the archwires used in vivo prevail. The bending testing was conducted by Elavyan [37], but only on aesthetic covered archwires collected from patients with minor crowding, without any extractions of premolars treated with fixed devices. Also, the studies of Eliades $[36,41]$ tried to determine whether the complex conditions of the oral cavity lead to the deterioration of the surface properties of the archwires and also to correlate the changes in topography with those of structural composition.

The surface topography of the orthodontic archwires is an essential property, having the ability to influence the mechanical characteristics, the appearance, corrosion and their biocompatibility. The result of the surface structure depends on several factors including: the alloy used in manufacturing, the complex manufacturing process and the finishing treatment of the surface $[44,45]$.

Thus, we considered useful to undertake a study which would include the analysis of the orthodontic intraorally used archwires as compared to the new ones and those used in vitro. This experimental study mainly aims at highlighting and comparing the most important mechanical properties of the new (as-received) orthodontic archwires, of those immersed in fluorinated solution, of the as-retrieved ones and of the intra-orally used ones (made of SS, NiTi, $\beta$-Ti and aesthetic NiTi). A microscopic characterization of these archwires was also intended, in terms of surface topography. The null hypothesis is that immersion and intra-oral use does not alter the mechanical properties and the surface topography of these archwires.

\section{Materials and methods}

The archwires tested were: NiTi and SS of 0.016 inch and of $0.016 \times 0.022 \mathrm{inch}$, as well as $\beta$-Ti of $0.016 \times 0.022$ inch and physiognomic NiTi (Phys-NiTi) of 0.016 inch. A total of 270 archwires were mechanically tested. All archwires were taken from the same manufacturer, GAC Company (GAC-DENTSPLY Corporate, York, USA) and from the same batch, to eliminate the possible variations due to different batches. The archwires were divided into three categories, as follows: new archwires, immersed archwires and intra-orally (IO) used archwires.

The new archwires were mechanically tested immediately after removing the protective packaging material. The immersed archwires were placed in hermetically sealed plastic containers and then incubated at $37^{\circ} \mathrm{C}$ for 7 days in the laboratory thermostat (WB Falc M5, Falc Instruments Italy). The permanent monitoring of the temperature was using a digital thermometer and there were no registered variations over $\pm 1^{\circ} \mathrm{C}$.

The solutions used for immersion had the following composition:

- Coca-Cola: phosphoric acid, sugar, carbon dioxide, flavors, $\mathrm{pH}=2.6$

- Local fluorination agent in the form of a gel (Home care fluoride gel, Dental Technologies, Illinois, USA): $0.4 \%$ stannous fluoride, ascorbic acid, citric acid, flavors, glycerin and carbomer.

The amount of immersion solution in each container was $4 \mathrm{ml}$, to ensure the full immersion of the archwires. At the same time, every 24 hours the solutions were changed. At the end of the period of immersion, the archwires were washed with distilled water and placed in new packages individually marked.

The archwires used in vivo were collected from 21 patients treated with fixed orthodontic devices by the orthodontist. The criteria of patient selection were: 
- The treatment with fixed maxillary and mandible device, brackets used according to Roth prescription, the use of a slot of 0.018 inch, metal or elastic ligatures

- Close age range of patients (14-25 years old)

- The lack of labio-maxillo-palatal clefts or of other craniofacial syndromes

- Cooperating patients

- Good or satisfactory oral hygiene

- The lack of general conditions which may quantitatively and qualitatively influence the salivary secretion (E.g. xerostomia, diabetes etc.)

After collection, the archwires were washed with distilled water and placed in packs labeled with the name of the patient, the size and type of the arch (alloy, the upper or lower arch), the application and removal date of the arch. The archwires were grouped into two categories, depending on the intra-oral time of use, as follows:

a. Intra-oral archwires used for 4-6 weeks (having the call sign IO-1 month)

b. Archwires used for more than 6 weeks into the oral cavity (having the call sign IO-2 months)

The determination of mechanical characteristics was performed by tensile test and three-point bending test, using an Instron universal machine (Instron, type 3366 Norwood, MA) equipped with Instron Bluehill 2 software. For each type of arch there were 5 specimens subjected to the test.

\section{Tensile test}

In order to achieve the tensile test, the ends of the specimens were fixed into the jaws of the testing machine, so that the distance between the reference marks (gauge length) was $40 \mathrm{~mm}$. The moving speed of the crosshead was set at $1 \mathrm{~mm} / \mathrm{min}$. The tensile-strain diagrams (stress-strain) were obtained and the yield strength (YS), the ultimate tensile strength (UTS) and the modulus of elasticity (E) were calculated. The yield strength was calculated for a specific deformation of $0.2 \%$. The tensile testing of the NiTi archwires of 0.016 inch physiognomic recovered could not be achieved. We were unable to exactly determine the break resistance value while using tensile tests due to some technical difficulties, these archwires sliding out from the fixing bracket. Unlike the new archwires, in which the distal portion attached to the clamping jaws of the test machine was not covered by the aesthetic coating, in those placed into the oral cavity, this portion of the arch was cut out. Thus, when using the tensile test, the Teflon coating broke away from the metal surface of the arch. The intraorally used $\beta$-Ti archwires were not sufficient in number to be tested for tensile strength.

\section{The bending test}

The bending characteristics (activation and deactivation forces) were determined by using a threepoint bending test (Miura et al., modified by Krishnan and Kumar [2,9]). In order to be tested, the archwires were inserted into the slot of some edgewise type brackets
(3B STD Edgewise, GAC International TM), fixed with elastic ligatures, glued on an aluminum backing, specially conformed for the bending test. The brackets subject to the bending test were placed so that the inter-brackets segment distance was $14 \mathrm{~mm}$. The aluminum support was attached to the lower jaw of the testing machine. To the upper jaw of the testing machine a metal blade with a curvature of 1 $\mathrm{mm}$ at the end was attached. Using this blade, the bending test of the archwires was performed in their middle portion. From each specimen the relatively straight, distal portions were tested. The NiTi and physiognomic NiTi archwires were bent up to 1 and $4 \mathrm{~mm}$ respectively, while those made of SS were bent only up to $1 \mathrm{~mm}$. We did not find it useful to bend them at higher values, as these archwires are not subject to bigger bending values into the oral cavity.

The statistical analysis was performed using the Excel program for Windows and the test used was the $t$ Student test, $\mathrm{p} \leq 0.05$ significance level. This test was used to determine if the two sets of data were significantly different from each other. Another reason for using this test was because it is the most commonly applied when the test statistic would follow a normal distribution if the value of a scaling term in the test statistic were known. Descriptive analysis was also done, mean and standard deviations were calculated.

The study of the surface topography was done by Scanning Electronic Microscope (SEM) and optical analysis. A FEI Quanta 3D scanning electronic microscope was used to highlight the micro-morphological characteristics of the surface of the archwires. The magnifications used were from $\times 200$ to $\times 3000$. The optical microscope (MO) used to the study the archwires was an Olympus GX 51.

Basically, two specimens from each type of arch, randomly chosen, both new (as received) as well as the immersed ones and the intra-orally used ones were subjected to microscopic examinations. From each specimen the straight distal parts were cut out (two), at approximate $20 \mathrm{~mm}$. One of the fragments was analyzed with the optical microscope and the second one with an electronic microscope.

\section{Results \\ Mechanical testing}

The results of the tensile test upon the new and immersed archwires as well as the level of significance (p) obtained from a comparative statistical analysis between new and immersed archwires are shown in Tables I, II and III.

The activation and deactivation values of the forces obtained from the bending test are graphically presented in Figure 1 for the Phys-NiTi archwires, in Figure 2 for the $0.016 \times 0.022$ NiTi ones, in Figures 3 and 4 for the SS ones and tabular given for the round $\mathrm{NiTi}$ and rectangular $\beta-\mathrm{Ti}$ archwires (Tables IV and V). 
Table I. The results of the tensile tests upon the new and immersed NiTi archwires.

\begin{tabular}{|c|c|c|c|c|c|c|}
\hline Property & $\begin{array}{l}\text { NiTi } \\
\text { New } 0.016 \times 0.022\end{array}$ & $\begin{array}{l}\text { Niti } \\
\text { Coke } 0.016 x 0.022\end{array}$ & $\begin{array}{l}\text { Niti } \\
\text { Fluorine } 0.016 \times 0.022\end{array}$ & $\begin{array}{l}\text { NiTi } \\
\text { New } 0.016\end{array}$ & $\begin{array}{l}\text { Niti } \\
\text { Coke } 0.016\end{array}$ & $\begin{array}{l}\text { Niti } \\
\text { Fluorine } 0.016\end{array}$ \\
\hline Yield strength & $320.79 \pm 30.87$ & $\begin{array}{l}374.89 \pm 15 \\
\mathrm{p}=0.0543\end{array}$ & $\begin{array}{l}97368.68 \pm 4.08 \\
\mathrm{p}=0.0708\end{array}$ & $334.03 \pm 9.8$ & $\begin{array}{l}383.01 \pm 18.27 \\
\mathrm{p}=0.0149\end{array}$ & $\begin{array}{l}358.63 \pm 12.07 \\
\mathrm{p}=0.0519\end{array}$ \\
\hline Ultimate Tensile strength & $1252.8 \pm 23.14$ & $\begin{array}{l}1324.12 \pm 23.53 \\
p=0.0200\end{array}$ & $\begin{array}{l}1318.1 \pm 12.37 \\
p=0.0125\end{array}$ & $1257.31 \pm 25.34$ & $\begin{array}{l}1320.24 \pm 15.56 \\
p=0.0214\end{array}$ & $\begin{array}{l}1268.53 \pm 9.44 \\
p=0.5121\end{array}$ \\
\hline Elastic modulus & $\begin{array}{l}24837.42 \\
\pm 1227.46\end{array}$ & $\begin{array}{l}28097.99 \pm 885.46 \\
p=0.0202\end{array}$ & $\begin{array}{l}28375.64 \pm 345.05 \\
p=0.0086\end{array}$ & $\begin{array}{l}30187.38 \\
\pm 1932.17\end{array}$ & $\begin{array}{l}33858.24 \\
\pm 1019.67 \\
p=0.3740\end{array}$ & $\begin{array}{l}31348.77 \\
\pm 562.5 \\
p=0.3740\end{array}$ \\
\hline
\end{tabular}

Table II. The results of the tensile tests upon the new and immersed SS archwires.

\begin{tabular}{|c|c|c|c|c|c|c|}
\hline Property & $\begin{array}{l}\text { SS } \\
\text { New 0.016x0.022 }\end{array}$ & $\begin{array}{l}\text { SS } \\
\text { Coke 0.016x0.022 }\end{array}$ & $\begin{array}{l}\text { SS } \\
\text { Fluorine } 0.016 \times 0.022\end{array}$ & $\begin{array}{l}\text { SS } \\
\text { New } 0.016\end{array}$ & $\begin{array}{l}\text { SS } \\
\text { Coke } 0.016\end{array}$ & $\begin{array}{l}\text { SS } \\
\text { Fluorine }\end{array}$ \\
\hline Yield strength & $1766.7 \pm 189.9$ & $\begin{array}{l}2064.57 \pm 40.49 \\
\mathrm{p}=0.0273\end{array}$ & $2065.56 \pm 9.91 \mathrm{p}=0.5496$ & $2188.11 \pm 58.13$ & $\begin{array}{l}2261.91 \pm 14.94 \\
\mathrm{p}=0.0250\end{array}$ & $\begin{array}{l}2283.86 \pm 43.95 \\
p=0.0187\end{array}$ \\
\hline $\begin{array}{l}\text { Ultimate Tensile } \\
\text { strength }\end{array}$ & $1820.4 \pm 163.35$ & $\begin{array}{l}2068.24 \pm 36.01 \\
p=0.0138\end{array}$ & $2065.56 \pm 9.91 \mathrm{p}=0.0117$ & $2188.11 \pm 58.13$ & $\begin{array}{l}2261.91 \pm 14.94 \\
p=0.0250\end{array}$ & $\begin{array}{l}2283.86 \pm 43.95 \\
\mathrm{p}=0.0187\end{array}$ \\
\hline Elastic modulus & $\begin{array}{l}133264.79 \\
\pm 6254.9\end{array}$ & $\begin{array}{c}113622.85 \\
\pm 1609.06 \\
\mathrm{p}=0.0004\end{array}$ & $\begin{array}{l}111684.27 \\
\pm 198.2 \\
\mathrm{p}=0.0007\end{array}$ & $\begin{array}{l}113279.85 \\
\pm 5514.65\end{array}$ & $\begin{array}{c}120662.98 \\
\pm 1161.13 \\
p=0.0190\end{array}$ & $\begin{array}{c}125862.61 \\
\pm 2145.38 \\
\mathrm{p}=0.0014\end{array}$ \\
\hline
\end{tabular}

Table III. The results of the tensile tests upon the new and immersed $\beta$-Ti and Phys -NiTi archwires.

\begin{tabular}{|c|c|c|c|c|c|c|}
\hline Property & $\begin{array}{l}\beta \text {-Ti } \\
\text { New } 0.016 \times 0.022\end{array}$ & $\begin{array}{l}\beta \text {-Ti } \\
\text { Coke } 0.016 \times 0.022\end{array}$ & $\begin{array}{l}\beta \text {-Ti } \\
\text { Fluorine } 0.016 \times 0.022\end{array}$ & $\begin{array}{l}\text { Fiz-NiTi } \\
\text { New } 0.016\end{array}$ & $\begin{array}{l}\text { Fiz-NiTi } \\
\text { Coke } 0.016\end{array}$ & $\begin{array}{l}\text { Fiz-NiTi } \\
\text { Fluorine } 0.016\end{array}$ \\
\hline Yield strength & $1156.71 \pm 30.37$ & $\begin{array}{l}1307.8 \pm 16.54 \\
p=0.0049\end{array}$ & $\begin{array}{l}1312.38 \pm 18.44 \\
\mathrm{p}=0.0051\end{array}$ & $200.99 \pm 11.09$ & $\begin{array}{l}180.12 \pm 28.05 \\
\mathrm{p}=0.4072\end{array}$ & $222.4 \pm 7.43 \mathrm{p}=0.1515$ \\
\hline $\begin{array}{l}\text { Ultimate Tensile } \\
\text { strength }\end{array}$ & $1156.71 \pm 30.37$ & $\begin{array}{l}1307.8 \pm 16.54 \\
p=0.0049\end{array}$ & $\begin{array}{l}1312.38 \pm 18.44 \\
p=0.0051\end{array}$ & $649.34 \pm 98.01$ & $\begin{array}{l}794.86 \pm 139.55 \\
p=0.2989\end{array}$ & $\begin{array}{l}844.61 \pm 152.39 \\
p=0.2669\end{array}$ \\
\hline Elastic modulus & $\begin{array}{l}40975.26 \\
\pm 2049.19\end{array}$ & $\begin{array}{l}46798.69 \\
\pm 471.72 \\
p=0.0143\end{array}$ & $\begin{array}{l}46682.29 \\
\pm 304.68 \\
p=0.014\end{array}$ & $\begin{array}{l}23291.33 \\
\pm 344.62\end{array}$ & $\begin{array}{l}19951.31 \\
\pm 3042.69 \\
p=0.2383\end{array}$ & $\begin{array}{l}23496.29 \\
\pm 2058.55 \\
p=0.9022\end{array}$ \\
\hline
\end{tabular}

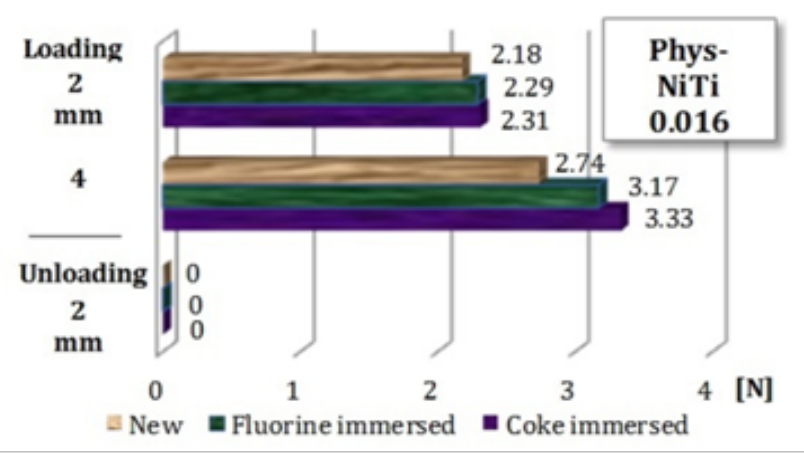

Figure 1. A comparative diagram of the bending test at $4 \mathrm{~mm}$ of Phys - NiTi 0016 for new and immersed archwires.

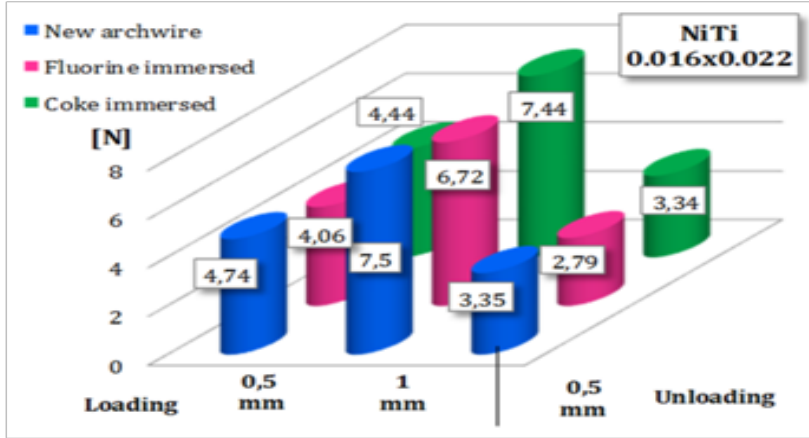

Figure 2. Bending testing for the new and immersed archwires - 1 mm NiTi 0.016x0.022. 


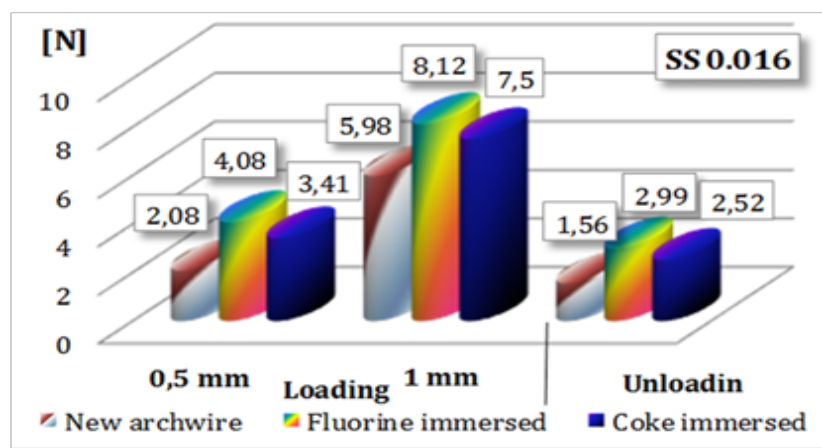

Figure 3. A comparative diagram of the bending tests at $1 \mathrm{~mm}$ of the new and immersed SS 0.016 archwires.

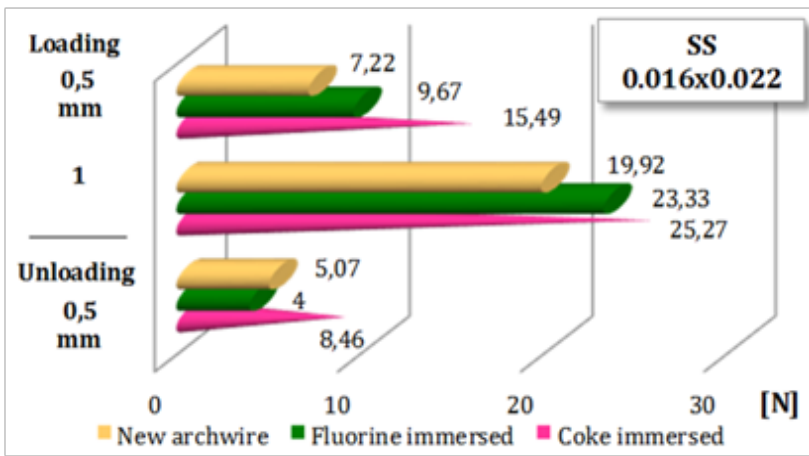

Figure 4. A comparative diagram of the bending tests at $1 \mathrm{~mm}$ of the SS $0.016 \times 0.022$ new and immersed archwires.

Table IV. The bending test results of 0016 NiTi new and immersed archwires.

\begin{tabular}{lccc}
\hline NiTi 0.016 & New archwires & Fluorine immersed archwires & Coke immersed arch wires \\
\hline Loading $0.5 \mathrm{~mm}$ & $0.86 \pm 0.225$ & $1.16 \pm 0.109$ & $1.41 \pm 0.124$ \\
\hline Loading $1 \mathrm{~mm}$ & $2.44 \pm 0.192$ & $2.63 \pm 0.195$ & $2.83 \pm 0.117$ \\
\hline Unloading $0.5 \mathrm{~mm}$ & $0.55 \pm 0.207$ & $0.69 \pm 0.064$ & $0.96 \pm 0.121$ \\
\hline Loading $2 \mathrm{~mm}$ & $3.46 \pm 0.301$ & $3.65 \pm 0.029$ & $3.62 \pm 0.147$ \\
\hline Loading $4 \mathrm{~mm}$ & $4.38 \pm 0.343$ & $4.83 \pm 0.149$ & $4.68 \pm 0.051$ \\
\hline Unloading $2 \mathrm{~mm}$ & $0.73 \pm 0.165$ & $0.59 \pm 0.25$ & $0.98 \pm 0.06$ \\
\hline
\end{tabular}

Table V. The bending test results at $4 \mathrm{~mm}$ for the new and immersed $\beta$ - Ti $0.016 \mathrm{x} 0.022 \mathrm{arch}$.

\begin{tabular}{lccc}
\hline $\boldsymbol{\beta}$-Ti 0.016x0.022 & New & Fluorine & Coke \\
\hline Loading $2 \mathrm{~mm}$ & $13.43 \pm 0.226$ & $20.68 \pm 0.157$ & $17.62 \pm 0.659$ \\
\hline Loading $4 \mathrm{~mm}$ & $14.21 \pm 0.099$ & $26.41 \pm 0.511$ & $21.76 \pm 0.14$ \\
\hline Unloading $2 \mathrm{~mm}$ & $1.51 \pm 0.117$ & $1.31 \pm 0.38$ & $0.14 \pm 0.24$ \\
\hline
\end{tabular}

Table VI. The tensile test results for the intra-orally used NiTi archwires.

\begin{tabular}{|c|c|c|c|c|}
\hline Arch wire & Treatment & Yield strength & Tensile strength & Elastic modulus \\
\hline $\begin{array}{l}\mathrm{NiTi} \\
0.016\end{array}$ & $\begin{array}{l}\text { New archwires } \\
\text { IO - } 1 \text { month }\end{array}$ & $\begin{array}{l}334.03 \pm 9.8 \\
322.26 \pm 51.24 \\
p=0.7169\end{array}$ & $\begin{array}{l}1257.31 \pm 25.34 \\
1210.91 \pm 70.17 \\
p=0.3327\end{array}$ & $\begin{array}{l}30187.38 \pm 1932.17 \\
27069.04 \pm 2410.55 \\
p=0.1268\end{array}$ \\
\hline $\begin{array}{l}\mathrm{NiTi} \\
0.016\end{array}$ & $\begin{array}{l}\text { New archwires } \\
\text { IO }-2 \text { months }\end{array}$ & $\begin{array}{l}334.03 \pm 9.8 \\
306.26 \pm 10.11 \\
p=0.0268\end{array}$ & $\begin{array}{l}1257.31 \pm 25.34 \\
1232.48 \pm 28.22 \\
p=0.3202\end{array}$ & $\begin{array}{l}30187.38 \pm 1932.17 \\
27286.98 \pm 4088.46 \\
p=0.3288\end{array}$ \\
\hline NiTi $0.016 \times 0.022$ & $\begin{array}{l}\text { New archwires } \\
\text { IO - } 1 \text { month }\end{array}$ & $\begin{array}{l}320.79 \pm 30.87 \\
320.63 \pm 60.39 \\
p=0.9969\end{array}$ & $\begin{array}{l}1252.8 \pm 23.14 \\
1180.53 \pm 206.88 \\
p=0.5800\end{array}$ & $\begin{array}{l}24837.42 \pm 1227.46 \\
23164.29 \pm 3964.42 \\
p=0.5234\end{array}$ \\
\hline NiTi $0.016 \times 0.022$ & $\begin{array}{l}\text { New archwires } \\
\text { IO }-2 \text { months }\end{array}$ & $\begin{array}{l}320.79 \pm 30.87 \\
221.19 \pm 7.3 \\
p=0.0055\end{array}$ & $\begin{array}{l}1252.8 \pm 23.14 \\
1170.58 \pm 14.38 \\
\mathrm{p}=0.0064\end{array}$ & $\begin{array}{l}24837.42 \pm 1227.46 \\
19881.19 \pm 1189.16 \\
p=0.0073\end{array}$ \\
\hline
\end{tabular}

Table VII. The results of the tensile tests of the SS intra-orally used archwires.

\begin{tabular}{lllll}
\hline Arch wire & Treatment & Yield strength & Tensile strength & Elastic modulus \\
\hline \multirow{3}{*}{ SS 0.016 } & New archwires & $2188.11 \pm 58.13$ & $2188.11 \pm 58.13$ & $113279.85 \pm 5514.65$ \\
& IO -1 month & $\begin{array}{l}1992.88 \pm 74.47 \\
\mathrm{p}=0.0129\end{array}$ & $\begin{array}{l}2012.44 \pm 28.67 \\
\mathrm{p}=0.0030\end{array}$ & $\begin{array}{l}98089.55 \pm 10957.2 \\
\mathrm{p}=0.0365\end{array}$ \\
\hline \multirow{3}{*}{ SS 0.016 } & New archwires & $2188.11 \pm 58.13$ & $2188.11 \pm 58.13$ & $113279.85 \pm 5514.65$ \\
& IO -2 months & $1987.33 \pm 10.86$ & $1987.33 \pm 10.86$ & $96331.2 \pm 3426.74$ \\
& & $\mathrm{p}=0.0058$ & $\mathrm{p}=0.0058$ & $\mathrm{p}=0.0111$ \\
\hline \multirow{3}{*}{ SS 0.016x0.022 } & \multirow{2}{*}{ New archwires } & $1766.7 \pm 189.9$ & $1820.4 \pm 163.35$ & $133264.79 \pm 6254.9$ \\
& IO -2 months & $1896.38 \pm 102$ & $1896.71 \pm 72.12$ & $75448.37 \pm 3704.84$ \\
& & $\mathrm{p}=0.4845$ & $\mathrm{p}=0.5002$ & $\mathrm{p}=0.0001$ \\
\hline
\end{tabular}


The results obtained from the tensile test for 0.016 inch archwires and $0.016 \times 0.022$ inch NiTi are listed in Table VI. In the case of 0.016 inch NiTi archwires, we notice a decrease in values of the three parameters but not a significant one from the statistical point of view.

The IO use of NiTi $0.016 \times 0.022$ inch archwires results in the reduction of the values of the three parameters, especially when using the archwires on periods longer than 6 weeks (Table VI).

In the case of SS steel 0.016 inch archwires the values of the three parameters were significantly decreased both after IO-1 month usage as well as in the case of the IO-2 months (Table VII).

Elastic modulus values of $0.016 \times 0.022$ inch SS IO-2 months archwires decreased significantly in comparison with those of new and immersed archwires. The values of the yield strength and of the tensile strength for the same archwires in comparison with those for the new arches did not significantly change.

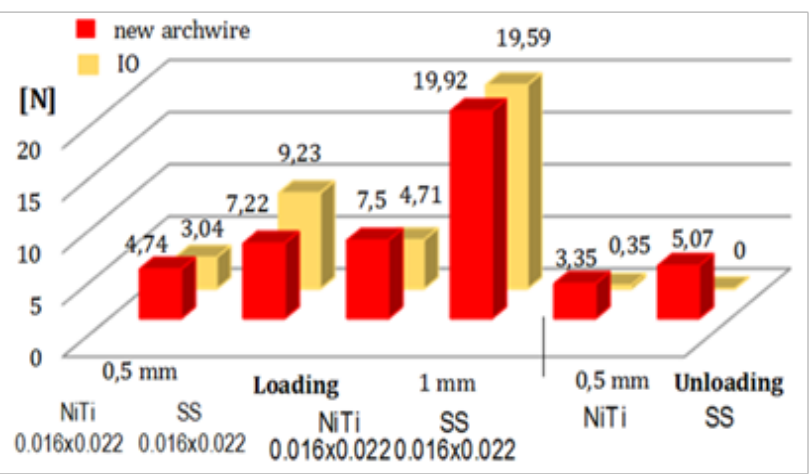

Figure 5. A comparative diagram of bending NiTi and SS rectangular archwires.

Table VIII. The bending test results of NiTi intra-orally used archwires.

\begin{tabular}{llll}
\hline NiTi 0.016 & $\begin{array}{l}\text { New } \\
\text { archwires }\end{array}$ & IO-1 month & Comparison \\
\hline Loading $0,5 \mathrm{~mm}$ & $0.86 \pm 0.225$ & $1.26 \pm 0.114$ & $\mathrm{p}=0.0509$ \\
\hline Loading $1 \mathrm{~mm}$ & $2.44 \pm 0.192$ & $2.47 \pm 0.353$ & $\mathrm{p}=0.9156$ \\
\hline Unloading $0,5 \mathrm{~mm}$ & $0.55 \pm 0.207$ & $0.6 \pm 0.185$ & $\mathrm{p}=0.7756$ \\
\hline Loading $2 \mathrm{~mm}$ & $3.46 \pm 0.301$ & $3.39 \pm 0.169$ & $\mathrm{p}=0.7250$ \\
\hline Loading $4 \mathrm{~mm}$ & $4.38 \pm 0.343$ & $4.72 \pm 0.105$ & $\mathrm{p}=0.1630$ \\
\hline Unloading $2 \mathrm{~mm}$ & $0.73 \pm 0.165$ & $0.45 \pm 0.127$ & $\mathrm{p}=0.0576$ \\
\hline & & & \\
\hline NiTi 0.016x0.022 & $\begin{array}{l}\text { New } \\
\text { archwires }\end{array}$ & IO 2 months & Comparison \\
\hline Loading $0,5 \mathrm{~mm}$ & $4.74 \pm 0.265$ & $3.04 \pm 0.01$ & $\mathrm{p}=0.0033$ \\
\hline Loading $1 \mathrm{~mm}$ & $7.5 \pm 0.246$ & $4.71 \pm 0.007$ & $\mathrm{p}=0.0006$ \\
\hline Unloading $0,5 \mathrm{~mm}$ & $3.35 \pm 0.173$ & $0.35 \pm 0.16$ & $\mathrm{p}=0.0003$ \\
\hline Loading $2 \mathrm{~mm}$ & $9.96 \pm 0.198$ & $9.41 \pm 0.705$ & $\mathrm{p}=0.3838$ \\
\hline Loading $4 \mathrm{~mm}$ & $12.04 \pm 0.328$ & $13.63 \pm 0.989$ & $\mathrm{p}=0.1270$ \\
\hline Unloading $2 \mathrm{~mm}$ & $5.11 \pm 0.073$ & $3.39 \pm 0.563$ & $\mathrm{p}=0.0266$ \\
\hline
\end{tabular}

Concerning the bending test, the results are shown in Figure 5. The activation and deactivation values of forces for intra-orally used archwires were compared with the values obtained from testing the new archwires of a corresponding size.

For the rectangular NiTi intra-orally used archwires used for more than 6 weeks a significant decrease in deactivation force was noticed from 5.11 to $3.39 \mathrm{~N}$ (Table VIII).

The results obtained from the bending test of SS intra-orally used (Table IX) showed that the values of the deactivation forces at $0.5 \mathrm{~mm}$ and $2 \mathrm{~mm}$ were 0 , significantly lower than in the case of the new archwires.

Table IX. The bending test results of SS 0016 intra-orally used archwires

\begin{tabular}{llll}
\hline SS 0.016 & $\begin{array}{l}\text { New } \\
\text { archwires }\end{array}$ & IO & Comparison \\
\hline Loading $0.5 \mathrm{~mm}$ & $2.08 \pm 1.31$ & $3.77 \pm 0.094$ & $\mathrm{p}=0.0904$ \\
\hline Loading $1 \mathrm{~mm}$ & $5.98 \pm 1.215$ & $7.44 \pm 0.489$ & $\mathrm{p}=0.1252$ \\
\hline Unloading $0.5 \mathrm{~mm}$ & $1.56 \pm 1.105$ & $0 \pm 0$ & $\mathrm{p}=0.0705$ \\
\hline
\end{tabular}

The esthetic NiTi intra-orally used archwires of 0.016 inch (Table X) developed activation forces to 2 and 4 $\mathrm{mm}$ bigger than the new ones, but, as in the case of the new archwires, the deactivation force at $2 \mathrm{~mm}$ was equal to 0 , basically these archwires not going back after stopping the force application.

Table X. The bending test results of Phys-NiTi intra-orally used archwires.

\begin{tabular}{llll}
\hline Phys-NiTi 0.016 & New archwires & IO & Comparison \\
\hline Loading $2 \mathrm{~mm}$ & $2.18 \pm 0.154$ & $2.57 \pm 0.136$ & $\mathrm{p}=0.0578$ \\
\hline Loading $4 \mathrm{~mm}$ & $2.74 \pm 0.02$ & $4.01 \pm 0.396$ & $\mathrm{p}=0.0233$ \\
\hline Unloading $2 \mathrm{~mm}$ & $0 \pm 0$ & $0 \pm 0.005$ & $\mathrm{p}=0.4950$ \\
\hline
\end{tabular}

\section{Surface analysis}

The figures $6 \mathrm{a}$ and $6 \mathrm{~b}$ present the scanning electron microscopy images and those of the optical microscopy ones for the as-received NiTi new archwires. Some striations parallel to the long axis of the arches, characteristic for the manufacturing process can be noticed on the surface of the new archwires. Also, minor circular defects can be observed which provides a marbled appearance, a rough aspect to the surface of the archwires.

The images of NiTi archwires immersed into a fluorinated solution and into a soft drink confirmed that the fluorinated solution affected the surface of the NiTi archwires forming a reaction products layer visible under the optical microscope (Figure 7a, 7b). The exposure of the archwires in the intra-oral environment determines significant changes in their surface topography, with the appearance of porous corrosion areas, friction areas and those in the form of cracks, visible both in SEM (Figure $7 \mathrm{c}$ ) and in MO. 


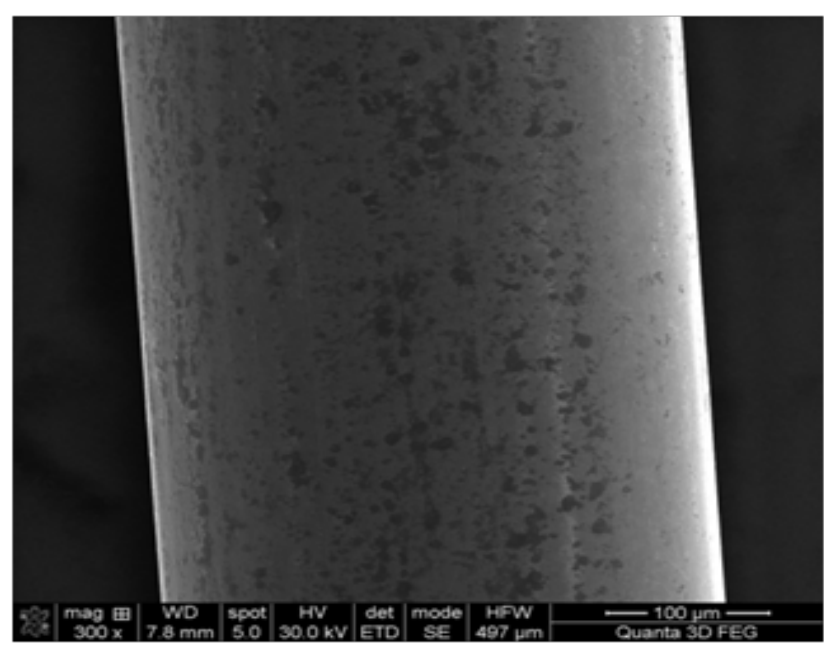

a

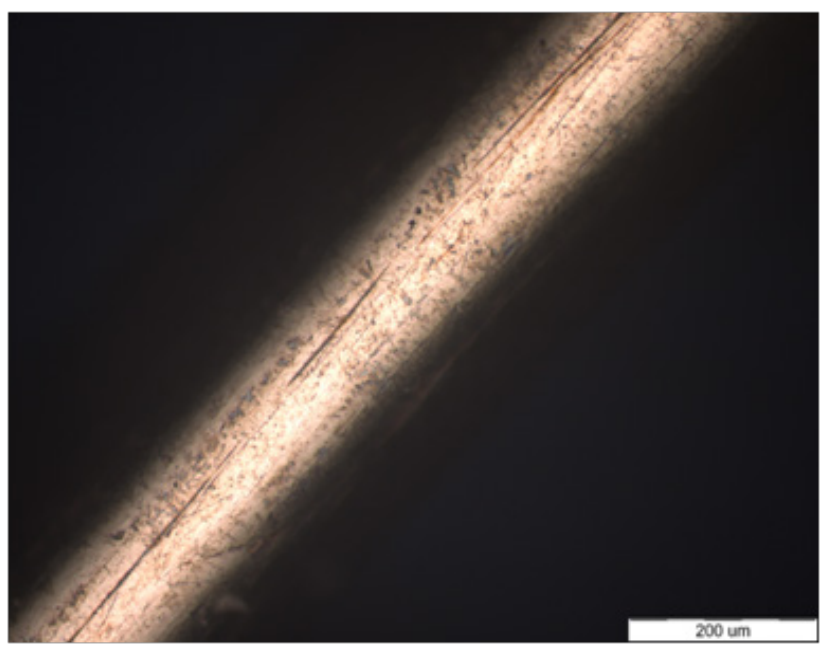

b

Figure 6. Scanning electron microscopy (x300) (a) and optical microscopy (b) images of NiTi new, as-received archwires

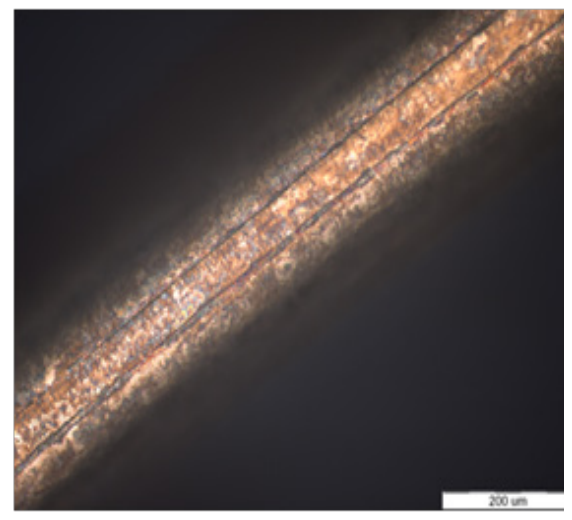

a

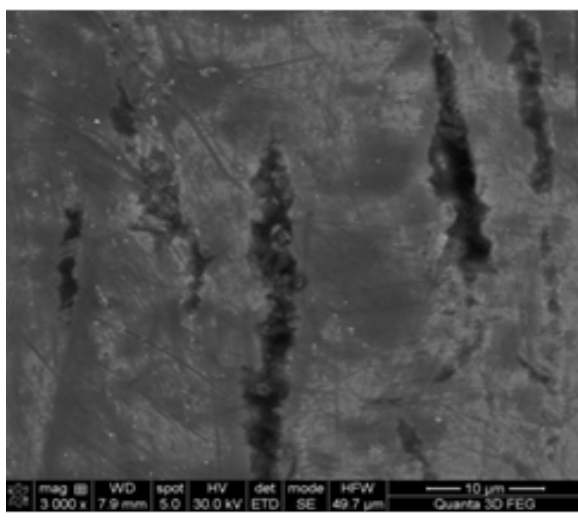

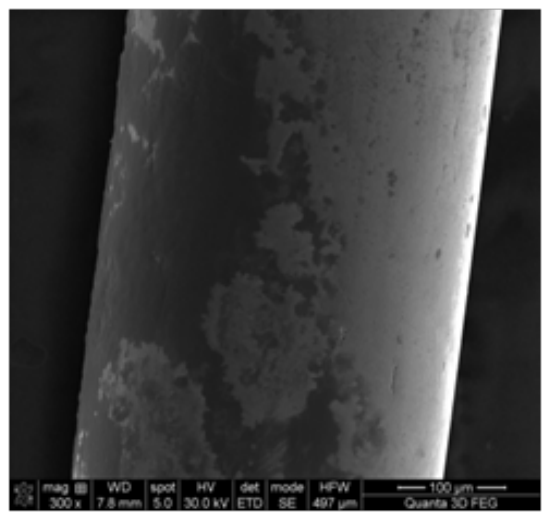

Figure 7. (a) MO image of the round $\mathrm{NiTi}$ arch wire immersed into topical fluoride solution, (b) SEM image of the same arch wire $\mathrm{x} 3000$, (c) SEM image of the intra-orally used NiTi arch wire x 300.

The new SS archwires studied in SEM reveals various topography but with the constant presence of the striations parallel to the long axis, characteristic of the manufacturing process (drawing) and the presence of micrometer cracks. The immersion of SS archwires in coke causes the appearance of some dark areas alternating with areas like those on the new archwires. The fluoride causes corrosion areas in forms of stains. The usage of the SS intra-oral archwires determined sharp changes of the surface characteristics. The SEM images (Figure 8a) highlight a growing and significant diversification of the surface defects due both to the handling of the archwires during their insertion and removing, as well as in the form of a uniform corrosion present on large areas. The frictional corrosion due to frictional forces occurring in the bracket arch interface is shown in Figure 8b, while the corrosion of aging with the occurrence of a crack is visible in Figure 8c.

The new $\beta$-Ti archwires (Figure 9a) presented a rough surface with many cracks. Out of all metallic archwires, these archwires have shown the most irregular surface. Their immersion into coke caused the occurrence of some corrosion areas (Figure $6.4 \mathrm{~b}$ ) while the fluoride deepened the fissure defects (Figure 9c). The use of intraoral archwires for a period of about six weeks led to a major damage of the archwires with the deposition of organic deposits and an obvious increase of the surface roughness (Figure 9d).

The new phys-NiTi archwires presented a porous surface structure. The aesthetic coating of these archwires provided a rough structure with numerous pores of variable sizes and an irregular surface highlighted in the SEM images (Figure 10a). The immersion of these archwires into coke determined the growth of the porous defects with a unifying tendency, while the fluoride determined the desquamation of the aesthetic cover, visible in figures $10 \mathrm{~b}$ and 10c. 


\section{Dental Medicine}
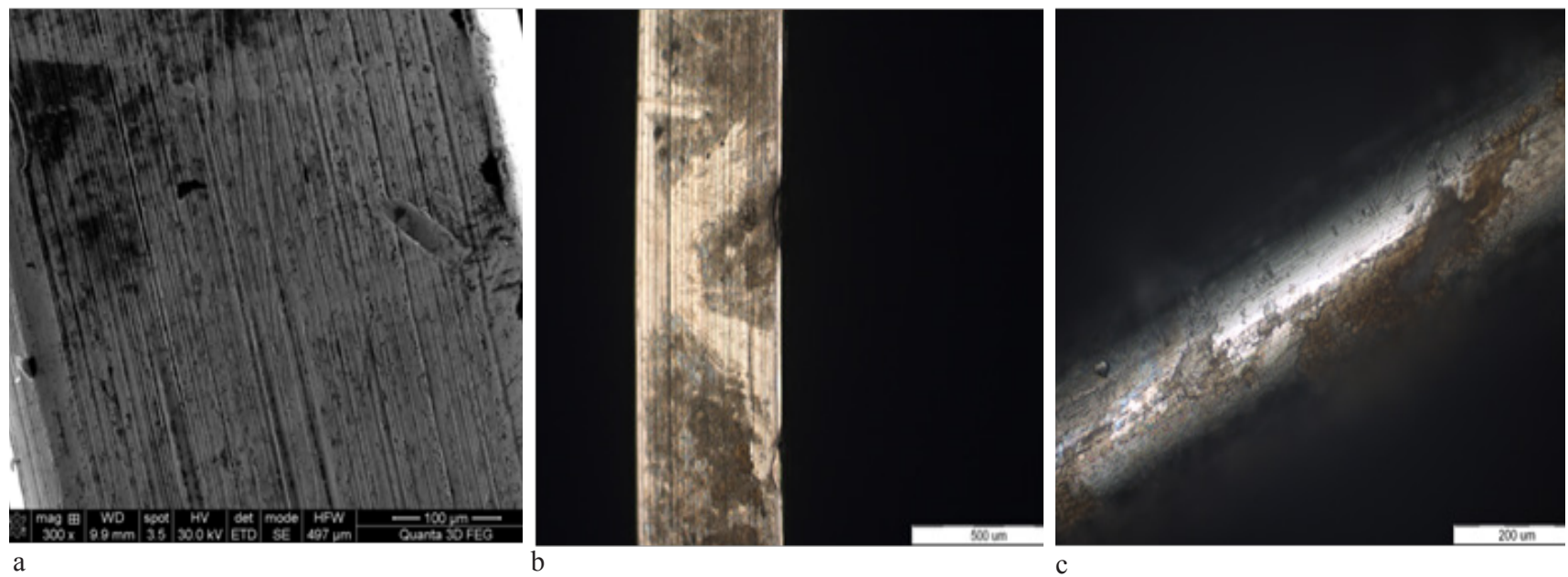

Figure 8. (a) SEM image of the IO SS rectangular arch wire; (b) Friction corrosion on the surface of the SS rectangular arch wire, IO; (c) MO image of SS Used intra-orally used round arch-wire.

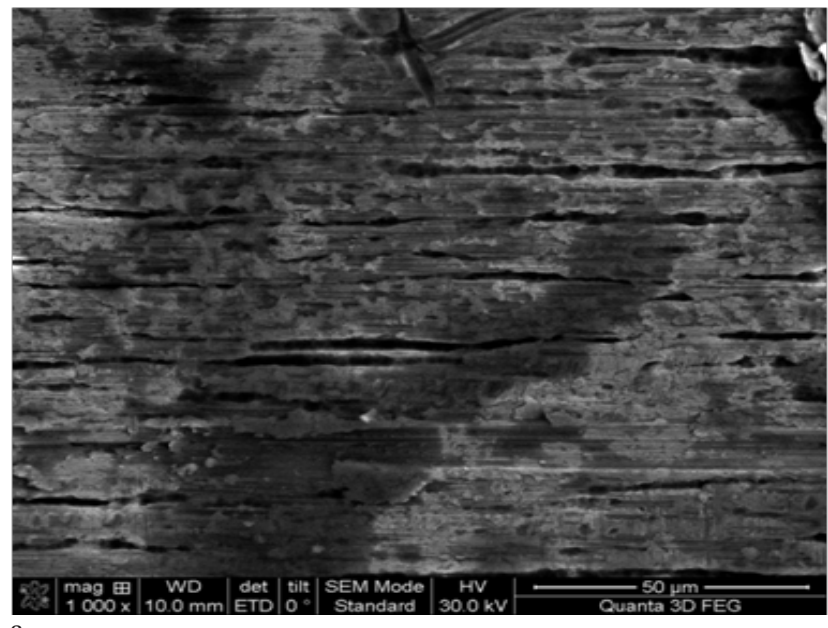

a

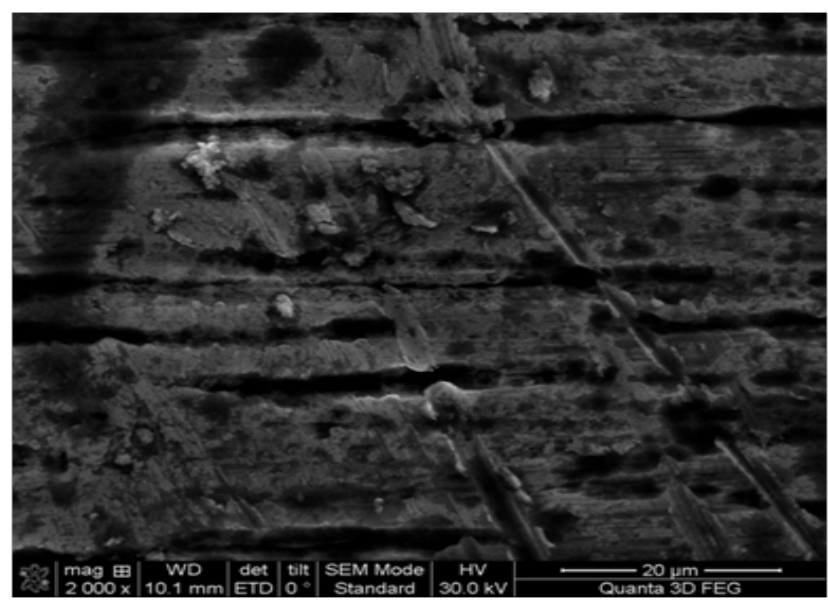

Figure 9. SEM images of the $\beta$-Ti arch-wires: (a) new, (b) immersed in soft drink, (c) topical fluoride immersed into solution, (d) intraorally used.

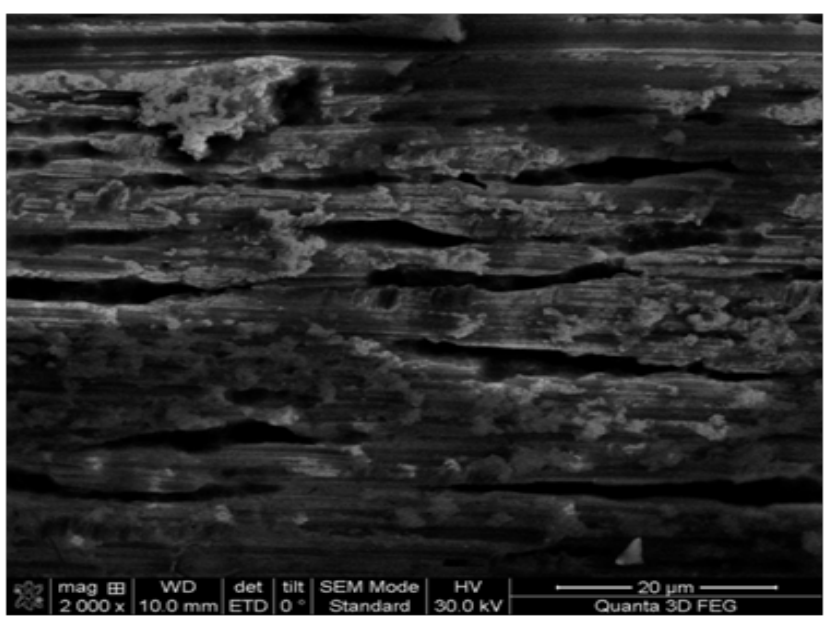

b

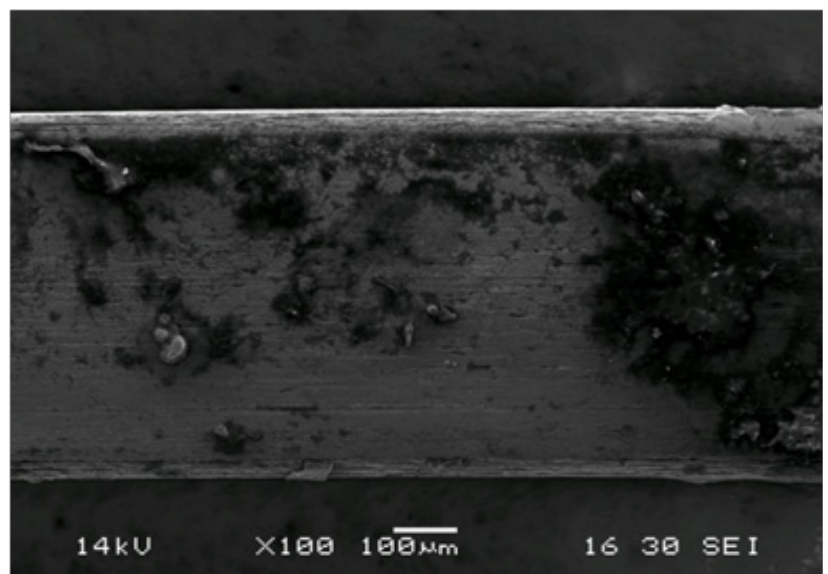

d 

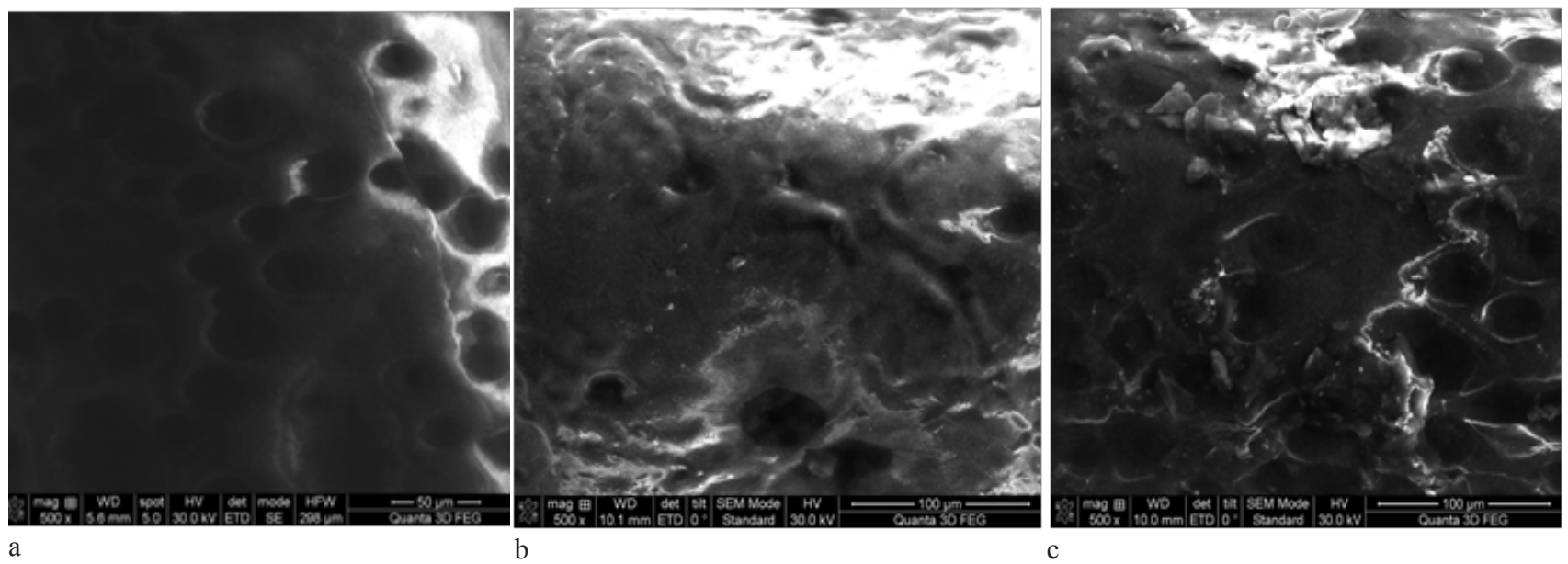

Figure 10. SEM images of the aesthetic NiTi arch-wires: (a) new, (b) immersed into coke, (c) immersed into topical fluoride solution.

A major damage of the aesthetic cover after the intra-oral usage was observed both for the MO and SEM investigations. These images highlight the desquamation on large areas of the aesthetic coating with the uncovering of the metal structure and signs of corrosion on the metal surface (Figure 11).

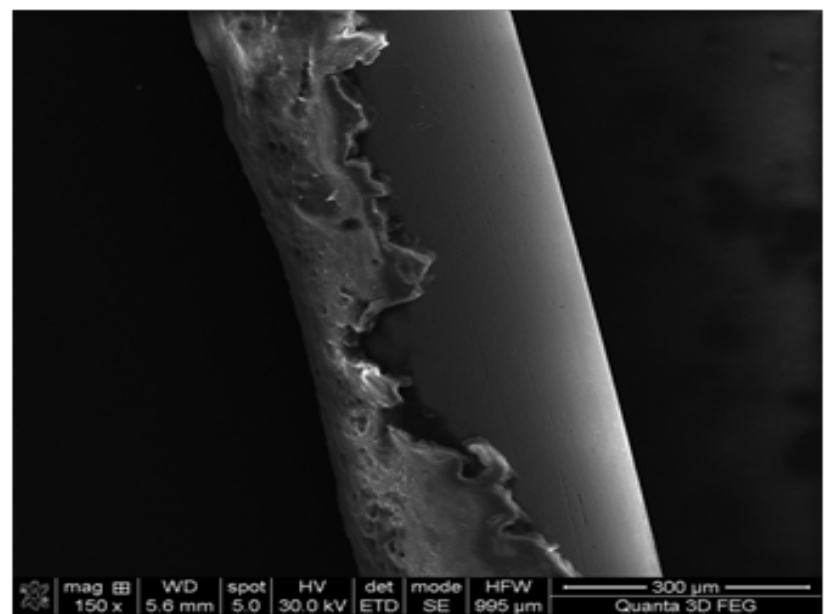

Figure 11. SEM image of an aesthetic NiTi arch wire intra-orally used.

\section{Discussion}

Numerous physical, chemical and biological factors may alter the mechanical properties of the orthodontic archwires. Also, the same factors determine variations in the frictional forces during the sliding biomechanics of the fixed orthodontic treatment. The correlation of the changes in the mechanical properties obtained after the traction test of the new and immersed archwires emphasizes the importance of the corrosion phenomena localized on the surface of the archwires and of the need of an accurate knowledge of their production mechanisms.
After this study, no significant changes in the tensile strength of the 0.016 inch NiTi archwires were observed. This result does not match with those obtained in the studies of Kaneko [20]. In his study, the archwires that have been evaluated were those of $0.016 \mathrm{inch}$, immersed into an acid solution of fluoride phosphate $2 \%$ concentration, while the incubation time was 60 minutes [20]. The differences in results may be due to different concentrations of the solution and the difference in the active substance concentration used. We have used a concentration of $0.4 \%$ fluoride for our experiment. Although the incubation time in different studies varies between 1-1.5 hours [18,20] to 1-28 days $[45,46]$, in the present study it was extended over a period of 7 days, corresponding to the usage of an arch wire in an intra-oral medium for about 5 months, using a fluorinated solution twice a day, with an action time of 30 minutes / application.

The effect of fluoride on the modulus of elasticity and on the tensile strength had been evaluated in a study by Hammad [15]. He distinguished no change in these properties after the immersion of the NiTi archwires, section 0.016 , into a $1.1 \%$ APF solution and a $\mathrm{pH}$ of 5.1.

The studies [18-24] that analyze the degradation of the protective oxide film on the surface of the orthodontic archwires as a result of their immersion into fluorinated solutions with increased hydrogen absorption and the consequent alteration of their mechanical performances, assume the existence of interference between the martensitic transformation mechanisms and the hydrogen ions. Thus, the increasing of the critical stress of the martensitic transformation by immersing the NiTi archwires may prevent the development of an appropriate orthodontic force.

In the case of the soft drinks, both the low $\mathrm{pH}$ of these solutions, as well as the total amount of acids are important factors in corrosion, as they determine the amount of hydrogen ions available to interact with the passive 


\section{Dental Medicine}

oxide layer [35]. The increased amount of phosphoric acid present into coke is responsible for the characteristic pattern of corrosion of the NiTi archwires. Coke, like the fluoride, seems to have a modifying effect on the elastic modulus, with its significant growth in the case of rectangular archwires (e.g. for the immersed 0.016x0.022 inch NiTi archwires, the modulus has increased from $24 \mathrm{MPa}$ for the new archwires to $28 \mathrm{MPa}$ for the archwires immersed into a fluorinated solution and $28 \mathrm{MPa}$ to those immersed into coke. The effect of the carbonated drinks on mechanical properties of the archwires has not been investigated in some other studies yet, most of the work focusing on their effect on the surface properties[35].

The immersion of $\beta$-Ti archwires with a section of $0.016 \times 0.022$ inch into the already mentioned solutions determined an increase of the tensile strength, as well as of the elastic modulus. These results differ from those obtained by Kaneko [20] as he obtained a reduction of the tensile strength of $\beta$-Ti archwires with $5.6 \%$ after their immersion into a fluorinated solution. On the other hand, Pernier et al. [47] have not revealed significant changes in the elastic modulus of Resolve archwires (Gac Company) after sterilization. The increasing of the values of these parameters cannot be attributed to the immersion solutions; these solutions cannot "improve" the qualities of the archwires, a more plausible explanation being the variations given by the manufacturing process, even in the case of archwires from the same batch.

The same authors [47] suggested that the autoclave sterilization at $134^{\circ} \mathrm{C}$ for 18 minutes does not determine variations of the elastic modulus in the case of SS archwires. On the other hand, Kaneko [20] has observed a slight decrease (with 2.6\%) of the ultimate tensile strength of the SS archwires with the size of 0.016 inch. According to their research, hydrogen absorption and corrosion occurrence in the form of cracks on the surface of the SS alloy are closely correlated and determine the alteration of mechanical properties and that of the ultimate tensile strength implicit [20]. However, they admit that this alteration of the mechanical properties is lower in the case of SS alloys when compared to those containing $\beta$-Ti and NiTi. These statements contradict those of Eliades et al. [40] according to whom corrosion does not affect the mechanical properties of the metallic alloy.

The results obtained from the three-point bending test, till $1 \mathrm{~mm}$ deformation of the immersed NiTi archwires does not indicate an alteration of forces intensity. On the contrary, the tendency is to increase the values of the forces. This aspect may be explained by corrosion phenomena induced by solutions with a consecutive alteration of the surface structure and an increase of the frictional force at the bracket-arch slot interface. Kusy [39] explained the complexity of the phenomena that should be taken into the calculation of the friction force developed at the interface between the bracket and the arch wire, factors such as partial overlapping areas and surface defects which significantly change the value of the frictional forces [39] and the force necessary to overcome the supplementary friction force explain the growth of these parameters.

The only arch that seems to be affected by fluoride in the sense of diminishing the forces is the $0.016 \times 0.022$ NiTi arch wire, but only to a bending up to $4 \mathrm{~mm}$, the deactivation force at $2 \mathrm{~mm}$ reducing from $5.11 \mathrm{~N}$ to 3.6 $\mathrm{N}(\mathrm{p}=0.001)$. A possible explanation is in the increased absorption of hydrogen in the area of contact with the fluoride.

The testing of the bending properties of the immersed archwires into coke has not been reported in the previous studies, the comparison of the obtained results with those from the literature not being possible.

The SS immersed archwires, both the round and the rectangular ones, showed the same tendency of increasing the activation and deactivation forces. The phenomenon of friction growth explains these increases, especially since many authors $[43,48-50]$ have noticed signs of corrosion on the surface of the immersed archwires into various solutions.

$\beta$-Ti archwires seem to be the most affected by the fluoride and coke immersion. Thus, the activation force to 2 and respectively $4 \mathrm{~mm}$ has grown, while the deactivation one significantly decreased in the case of the immersed into coke archwires, which reached only $0.14 \mathrm{~N}$ to $2 \mathrm{~mm}$. These results are according to those obtained by Walker [18]. According to his study, after the immersion into fluorinated solutions, the deactivation parameters (the elastic modulus and the breaking resistance to deactivation) decreased for the $\beta$-Ti archwires. The explanation may lie in the dissolution of the passive oxide film of the archwires having $\mathrm{Ti}$ in their composition under the action of the acidic solutions of fluoride.

The mechanical properties of $\beta$-Ti shall be modified due to hydrogen absorption after the degradation of the protective layer [20]. These reactions explain the degradation of the archwires immersed into fluorinated acidic solutions (APF), where the hydrofluoric acid is present, but not in the case of immersion into neutral solutions [18]. The immersion solution we have used, although it does not contain $\mathrm{H} 3 \mathrm{PO} 4$, has a $\mathrm{pH}$ of 4 , so it is acid. Watanabe et al. [19] did not observe changes in the roughness of the surface of the $\beta$-Ti archwires immersed into neutral solutions, but for those immersed into APF for 24 hours it statistically showed a significant increase in roughness.

After the three-point bending test of the immersed archwires aesthetically covered the value of the deactivation forces at $2 \mathrm{~mm}$ remained 0 , both for those immersed into coke as well as for those immersed into fluoride. Bandeira's study [51] on the frictional forces of the aesthetic archwires immersed into fluoride for 30 days showed a significant increase in the friction of the immersed archwires, growth 
explained by the increase of the roughening the surface of these archwires due to the acid attack. However, the immersion time in the case of our study was reduced. It was 7 days unlike the 30 days from Bandeira's study [51].

The study of dental and orthodontic materials paid a particular attention to the evaluation of the properties of the new archwires, while the changes that occurred after the use of the archwires in an intra-oral environment have been less investigated $[36,40,44,52]$. One of the few studies like this is that of Wickelhaus [52], about the surface roughness and the friction of the $0.016 \times 0.022$ inch, intra-orally used NiTi archwires. The SS archwires have been investigated by Marques [42], in terms of the surface roughness and friction. He observed a significant increase in the two parameters after the exposure for 8 weeks in an intra-oral environment.

The round NiTi intra-orally used archwires were divided into two categories, depending on the time of the intra-oral usage. Thus, the average values of the flow resistance, of the tensile breaking strength and of the elasticity modulus, even if they were lower than those of the new arches, there were no significant differences in statistical terms, regardless of the time of usage. This suggests that the use of round NiTi archwires for a long time in the intra-oral medium does not determine a significant alteration of these three parameters.

The most affected archwires seem to be the NiTi ones with the section of $0.016 \times 0.022$ used more than 6 weeks in an intra-oral environment. In their case, the values of these three parameters significantly decreased $(p<0.05)$. The results of our study are according with those of Zinelis et al. [44]. The authors have tested the fracture resistance of the new archwires and of those recovered by repeated application of the bending forces until their effective fracturing. They have concluded that the tensile strength drops to the rectangular or square archwires in comparison with the round NiTi archwires. Also, the breaking strength is higher when the new archwires are compared to those intra-orally used [44].

In contradistinction to NiTi archwires, the round SS ones are more affected after the intra-oral usage. Thus, the significant decrease of the flow resistance, of the tensile strength and of the elastic modulus of 0.016 inch SS arch wire has occurred whatever the time of the intra-oral usage was. As in the literature we found no studies to confirm or negate our results, we believe that the possible explanation for these decreased values could be the permanent (plastic) deformations produced during the ligatures of the archwires were made, but especially when exercising the chewing functions. These factors may cause deformation of the rounds section archwires and small dimensions, more than in the case of the bigger ones with a rectangular section. The macroscopic analysis of SS round archwires recovered from patients confirms the presence of these plastic deformations.
The tensile testing of the 0.016 inch esthetic NiTi archwires recovered could not be achieved. We were unable to determine the exact amount of tensile strength due to technical difficulties, these archwires sliding from fixing bracket. Unlike the new archwires where the distal portion attached to the clamping jaws of the test machine was not covered by the aesthetic coating, to those placed into the oral cavity this portion was cut out. Thus, during the tensile test Teflon coating broke away from the metallic surface.

The bending test of the orthodontic archwires with the activation and deactivation establishment of the forces are imposed by the last ISO specifications and because the deactivation forces are responsible for the tooth movement, they are of a major clinical importance.

In the case of NiTi round section archwires, the values of the deactivation forces to $2 \mathrm{~mm}$ have been significantly reduced. Eliades [41] said that after the intraoral exposure the surface topography of these archwires is significantly altered, with possible implications on their mechanical properties. Thus, by increasing the surface roughness determined by an appliance, the frictional force at the bracket- slot interface may increase [36,38]. After the deformation, the restoring force must overcome the additional frictional resistance from the slot. This explanation is valid for the rectangular archwires too, especially since the contact area between the arch and the slot and, implicitly, the friction surface are higher.

Significantly reduced values of the deactivation forces were obtained for the SS archwires. Both in the case of the round and rectangular archwires, the deactivation forces at $0.5 \mathrm{~mm}$ and $2 \mathrm{~mm}$ were equal to 0 . While for the SS archwires the deactivation force value 0 to $2 \mathrm{~mm}$ can be explained by the occurrence of permanent deformations. These distortions do not occur when bending the SS arches to $1 \mathrm{~mm}$ only [9]. The increase of the surface roughness and of the friction at the slot-arch interface is another factor that may reduce the average values of force deactivation. Marques' study [42] confirms this hypothesis, the author observing a $20.8 \%$ increase of the SS arch friction after 8 weeks of use in vivo. Also, some other studies $[38,42,53,54]$ confirm the correlation between the increases of the roughness due to intra-oral corrosion of the archwires based on an SS alloy.

Numerous studies $[37,40,45]$ have confirmed that the aesthetic coated archwires exposed in an intraoral environment suffer major deteriorations both of the mechanical properties and of the aesthetic ones as a result of the accentuated deterioration of the coating. The results of our study are according to the literature, the deactivation forces being zero like in the case of the archwires tested by Elavyan [37]. The same author has obtained higher values of the activation forces for the recovered archwires in comparison with the new ones, values that may be explained by the increased friction.

The analysis of the surface characteristics of the 


\section{Dental Medicine}

orthodontic archwires by means of optical and electronic microscopy revealed many differences, due to the alloy used in manufacturing, to the surface treatment, to the manufacturing process and to the environmental complexity in vitro or in vivo where these archwires are used.

In this study we observed many defects on the surface of the new SS round and rectangular archwires. These defects are presented in various forms and have a varied arrangement but most of them are parallel to the long axis of the archwires. Such defects as well as their correlation between their presence and the degradation of the archwires were also highlighted in the study by Paul et al. [53].

In the case of the SS archwires intra-orally used, we could detect many changes of the surface topography. Thus, on the SEM images, both signs of chemical degradation by corrosion with the occurrence of corrosion signs in the form of large circular areas which are joined together, as well as degradation signs through mechanical deformation in the form of scratches, especially at the bracket -arch interface can be observed. In contrast to other studies $[41,43]$, in this study, large deposits of organic material on the surface of the intra-orally used archwires were not observed, even if the extraction protocol of these archwires included the washing with distilled water only but not the cleaning with acid and alkaline solutions.

A previous study [18] on the effect of the fluorinated solutions on the surface of the SS archwires showed that after immersion, both the initial surface processed as well as the associated semicircular characteristics became more evident. A possible explanation of these changes may be the destruction of protective oxide coating layer. However, to confirm the presence of corrosion products associated with the fluoride some X-ray diffraction spectroscopy studies are needed [18].

After the immersion into a fluorinated solution, we detected similar changes to those in Walker's study [18]. The initial defects deepened and corrosion appeared in the form of stains.

We observed a greater alteration of the archwires immersed into the fluorinated solution compared with those immersed into coke. Thus, a stretching of the surface and a deepening of the cracks on the surface of the archwires could be highlighted. Also, on the MO images, the changes in the color of the NiTi archwires immersed into fluoride were highlighted, changes visible even by a human eye. Kaneko's study [20] has detected significant changes in the surface topography of the immersed archwires with the increasing of the roughness through corrosion of NiTi archwires, the occurrence of the uniform corrosion signs for the $\beta$-Ti archwires and signs of corrosion unevenly distributed on the surface of the SS archwires.

The effect of carbonated drinks on the enamel had been evaluated in several studies $[33,34]$, but their effect on orthodontic archwires had been evaluated in one study only by Abalos [35]. The results of that study show that carbonated drinks with a low $\mathrm{pH}$ have corrosive effects to the surface of NiTi archwires. The results of our study are according with those of Abalos [35], about the NiTi archwires affected by coke.

The investigated NiTi intra-orally used archwires revealed clear signs of uniform corrosion with the presence on small areas of organic deposits. The electron-microscopic investigations of the archwires intra-orally used conducted by Eliades [41] have shown that the formation of a film of organic substances on the surface of the NiTi archwires may cause an increased roughness of the surface and implicitly affect the sliding mechanics.

The microscopic analysis of the intra-orally used archwires was conducted in several studies $[37,46]$. These authors observed a loss of the aesthetic cover directly proportional to the time of the intra-oral usage. Thus, Elavyan [37], observed the damage to the coating with its loss in a proportion of $26 \%$ after a period of usage of 33 days. Our results are in accordance with those of Elavyan [37], the loss of the coating being directly proportional to the exposure time, although a significant damage was observed even when using the archwires for less than a month in an intra-oral environment.

\section{Conclusions}

a. Both the mechanical and surface properties are modified by the intra-oral usage of the archwires. These changes are more evident in the case of the archwires with an increased elastic modulus, most likely as a result of the plastic deformations that occurred due to their prolonged usage.

b. The change of the surface topography of the orthodontic archwires may determine changes of the bending characteristics by increasing the roughness of the surface.

c. The immersion into fluoride particularly affects the archwires containing Ti. Additional research of scanning differential calorimetry is needed to determine the complex mechanism by which the fluoride interferes with the transformations at the inter-atomic level.

d. The low efficiency of the NiTi aesthetic covered archwires observed during their intra-oral usage has been confirmed by all the mechanical tests conducted.

e. The existence of a correlation between the mechanical and surface properties of the intra-orally used arch wire is obvious in the sense of modifying the frictional characteristics to the slot- arch interface.

f. To increase the effectiveness of the archwires during the fixed orthodontic treatment it is recommended for the clinicians to monitor the dietary and hygiene habits of patients, as well as to shorten the time of the usage of the archwires in an intra-oral environment by changing them with new archwires. 


\section{References}

1. Kusy RP. A review of contemporary arch wires: their properties and characteristics. Angle Orthod. 1997;67(3):197-207.

2. Miura F, Mogi M, Ohura Y, Hamanaka H. The super-elastic property of the Japanese NiTi alloy wire for use in orthodontics. Am J Orthod Dentofacial Orthop. 1986;90(1):1-10.

3. Oltjen JM, Duncanson MG Jr, Ghosh J, Nanda RS, Currier GF. Stiffness-deflection behavior of selected orthodontic wires. Angle Orthod. 1997;67:209-218.

4. Johnson E, Lee RS. Relative stiffness of orthodontic wires. J Clin Orthod. 1989;23:353-363.

5. Kusy RP, Dilley GJ. Elastic modulus of a triple-stranded stainless steel arch wire via three- and four-point bending. J Dent Res. 1984;63:1232-1240.

6. Kusy RP, Stush AM. Geometric and material parameters of a nickel-titanium and a beta titanium orthodontic arch wire alloy. Dent Mater. 1987;3:207-217.

7. Goldberg AJ, Burstone CJ. Status report on beta-titanium orthodontic wires. Council on Dental Materials, Instruments, and Equipment. J Am Dent Assoc. 1982;105:684-685.

8. Garrec P, Jordan L. Stiffness in bending of a superelastic NiTi orthodontic wire as a function of cross-sectional dimension. Angle Orthod. 2004;74:691-696.

9. Krishnan V, Kumar KJ. Mechanical properties and surface characteristics of three arch wire alloys. Angle Orthod. 2004;74:825-831.

10. Nakano H, Satoh K, Norris R, Jin T, Kamegai T, Ishikawa F, et al. Mechanical properties of several nickel-titanium alloy wires in three-point bending tests. Am J Orthod Dentofacial Orthop. 1999;115:390-395.

11. Parvizi F, Rock WP. The load/deflection characteristics of thermally activated orthodontic archwires. Eur J Orthod. 2003;25:417-421.

12. Bellini H, Moyano J, Gil J, Puigdollers A. Comparison of the superelasticity of different nickel-titanium orthodontic archwires and the loss of their properties by heat treatment. J Mater Sci Mater Med. 2016 Oct;27(10):158.

13. Obaisi NA, Galang-Boquiren MT, Evans CA, Tsay TG, Viana $\mathrm{G}$, Berzins D, et al. Comparison of the transformation temperatures of heat-activated Nickel-Titanium orthodontic archwires by two different techniques. Dent Mater. 2016;32(7):879-888.

14. Muguruma T, Iijima M, Yuasa T, Kawaguchi K, Mizoguchi I. Characterization of the coatings covering esthetic orthodontic archwires and their influence on the bending and frictional properties. Angle Orthod. 2016 Oct 12. [Epub ahead of print] 15. Hammad SM, Al-Wakeel EE, Gad el-S. Mechanical properties and surface characterization of translucent composite wire following topical fluoride treatment. Angle Orthod. 2012;82(1):813.

16. Graber TM, Vanarsdall RL Jr. Orthodontics. Current principles and techniques, 2nd edition, Mosby, Year Book Inc., St Louis University of Michigan; 1994, pp 233-238.

17. Proffit WR, Fields HW. Contemporary orthodontics. 3rd edition. Mosby, St. Louis, Mo, USA; 2000, pp 405-410.

18. Walker MP, Ries D, Kula K, Ellis M, Fricke B. Mechanical properties and surface characterization of beta titanium and stainless steel orthodontic wire following topical fluoride treatment. Angle Orthod. 2007;77(2):342-348.

19. Watanabe I, Watanabe E. Surface changes induced by fluoride prophylactic agents on titanium-based orthodontic wires. Am J Orthod Dentofacial Orthop. 2003;123:653-656.
20. Kaneko K, Yokoyama K, Moriyama K, Asaoka K, Sakai J. Degradation in performance of orthodontic wires caused by hydrogen absorption during short term immersion in $2.0 \%$ acidulated phosphate fluoride solution. Angle Orthod. 2004;74(4):487-495.

21. Nakagawa M, Matsuya S, Udoh K. Corrosion behavior of pure titanium and titanium alloys in fluoride-containing solutions. Dent Mater J. 2001;20:305-314.

22. Nakagawa M, Matsuya S, Udoh K. Effects of fluoride and dissolved oxygen concentrations on the corrosion behavior of pure titanium and titanium alloys. Dent Mater J. 2002;21:83-92. 23. Huang HH. Effects of fuoride concentration and elastic tensile strain on the corrosion resistance of commercially pure titanium. Biomaterials. 2002;23:59-63.

24. Huang HH. Electrochemical impedance spectroscopy study of strained titanium in fluoride media. Electrochim Acta. 2002;47:2311-2318.

25. Schiff N, Grosgogeat B, Lissac M, Dalard F. Influence of fluoride content and $\mathrm{pH}$ on the corrosion resistance of titanium and its alloys. Biomaterials. 2002;23:1995-2002.

26. Yokoyama K, Kaneko K, Moriyama K, Asaoka K, Sakai J, Nagumo M. Hydrogen embrittlement of Ni-Ti superelastic alloy in fluoride solution. J Biomed Mater Res A. 2003;65:182-187.

27. Kaneko K, Yokoyama K, Moriyama K, Asaoka K, Sakai J, Nagumo M. Delayed fracture of beta titanium orthodontic wire in fluoride aqueous solutions. Biomaterials. 2003;24:2113-2120.

28. Takemoto M, Shonohara T, Shirai M, Shinogaya T. External stress corrosion cracking (ESCC) of austenitic stainless steel. Mater Perf. 1985;24:26-32.

29. Zucchi F, Trabanelli G, Demertzis G. The intergranular stress corrosion cracking of a sensitized AISI 304 in $\mathrm{NaF}$ and $\mathrm{NaCl}$ solutions. Corros Sci. 1988;28:69-79.

30. Shibata $\mathrm{T}$, Haruna $\mathrm{T}$, Oki $\mathrm{T}$. Initiation and growth of intergranular stress corrosion cracks for sensitized 304 stainless steel depending on NaF concentration of aqueous solution. Tetusto-Hagane. 1993;79:721-725.

31. Yamazaki O. Effect of fluoride ion on the crevice corrosion for type 304 stainless steel in neutral $\mathrm{NaCl}$ solution. Zairyo-toKankyo. 1996;45:365-359.

32. Bastidas JM, Fosca C, Chico B, Otero E. Weight loss and electrochemical results for two super-austenitic stainless steels in chloride-fluoride mixtures. Corros Sci. 1996;38:559-563.

33. Van Eygen I, Vannet BV, Wehrbein H. Influence of a soft drink with low $\mathrm{pH}$ on enamel surfaces: an in vitro study. Am J Orthod Dentofacial Orthop. 2005,128(3):372-377.

34. von Fraunhofer JA, Rogers MM. Dissolution of dental enamel in soft drinks. Gen Dent. 2004;52:308-312.

35. Abalos C, Paul A, Mendoza A, Solano E, Palazon C, Gil FJ. Influence of soft drinks with low ph on different NiTi orthodontic arch-wire surface patterns. J Materi Eng and Perform. 2013;22:759.

36. Eliades $\mathrm{T}$, Bourauel C. Intraoral aging of orthodontic materials: the picture we miss and its clinical relevance. Am J Orthod Dentofacial Orthop. 2005;127(4):403-412.

37. Elayyan F, Silikas N, Bearn D. Mechanical properties of coated superelastic archwires in conventional and selfligating orthodontic brackets. Am J Orthod Dentofacial Orthop. 2010;137:213-217.

38. Reznikov N, Har-Zion G, Barkana I, Abed Y, Redlich M. Influence of friction resistance on expression of superelastic properties of initial NiTi wires in "reduced friction" and 
conventional bracket systems. J Dent Biomech. 2010;2010:613142. doi: 10.4061/2010/613142.

39. Kusy RP, Whitley JQ. Friction between different wire-bracket configurations and materials. Semin Orthod. 1997;3(3):166-177.

40. Eliades T, Athanasiou AE. In vivo aging of orthodontic alloys: implications for corrosion potential, nickel release, and biocompatibility. Angle Orthod. 2002;72:222-237.

41. Eliades T, Eliades G, Athanasiou AE, Bradley TG. Surface characterization of retrieved NiTi orthodontic archwires. Eur J Orthod. 2000;22(3):317-326.

42. Marques IS, Araújo AM, Gurgel JA, Normando D. Debris, roughness and friction of stainless steel archwires following clinical use. Angle Orthod. 2010;80(3):521-527.

43. Daems J, Celis JP, Willems G. Morphological characterization of as-received and in vivo orthodontic stainless steel archwires. Eur J Orthod. 2009,31(3):260-265.

44. Zinelis S, Eliades T, Pandis N, Eliades G, Bourauel C. Why do nickel-titanium archwires fracture intraorally? Fractographic analysis and failure mechanism of in-vivo fractured wires. Am J Orthod Dentofacial Orthop. 2007;132(1):84-89.

45. da Silva DL, Mattos CT, de Araújo MV, de Oliveira Ruellas AC. Color stability and fluorescence of different orthodontic esthetic archwires. Angle Orthod. 2013;83(1):127-132.

46. Trethewey KR, Chamberlain J. Crevice and pitting corrosion. Corrosion for Students of Science and Engineering. New York, NY: John Wiley \& Sons Inc; 1988,pp 134-149.
47. Pernier C, Grosgogeat B, Ponsonnet L, Benay G, Lissac M. Influence of autoclave sterilization on the surface parameters and mechanical properties of six orthodontic wires. Eur J Orthod. 2005;27(1):72-81.

48. Articolo LC, Kusy K, Saunders CR, Kusy RP. Influence of ceramic and stainless steel brackets on the notching of archwires during clinical treatment. Eur J Orthod. 2000;22(4):409-425.

49. Acharya A, Jayade VP. Metallurgical properties of stainless steel orthodontic arch wires: a comparative study. Trends Biomat Artif Organs 2005; 18(2): 125-136.

50. Kim H, Johnson JW. Corrosion of stainless steel, nickeltitanium, coated nickel-titanium and titanium orthodontic wires. Angle Orthod. 1999;69:39-44.

51. Bandeira AM, dos Santos MP, Pulitini G, Elias CN, da Costa MF. Influence of thermal or chemical degradation on the frictional force of an experimental coated NiTi wire. Angle Orthod. 2011;81(3):484-489.

52. Wichelhaus A, Geserick M, Hibst R, Sander FG. The effect of surface treatment and clinical use on friction in NiTi orthodontic wires. Dent Mater. 2005;21:938-945.

53. Paul A, Abalos C, Mendoza A, Solano E, Gil FJ. Relationship between the surface defects and the manufacturing process of orthodontic Ni-Ti archwires. Mater Lett. 2011;65(1):3358-3361. 54. Drescher D, Bourauel C, Schumacher HA. Frictional forces between bracket and arch wire. Am J Orthod Dentofacial Orthop, 1989;96(5):397-404. 